\title{
Dynamiques Professionnelles dans le champ de la santé
}

M.<smiles>C1CCC1</smiles>

Mme

Nom

Prénom

Organisme

Fonction

Adresse

Code Postal

Ville

Tél.

Fax

Courriel

J'assisterai au colloque le 23 mai 2005

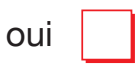

non

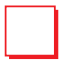

J'assisterai au colloque le 24 mai 2005

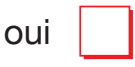

non

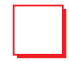

Je déjeunerai le 23 mai 2005

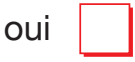

non $\square$

Je donne mon accord pour que l'on communique mes coordonnées aux autres participants

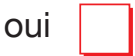

non

Merci de bien vouloir retourner avant le

Vendredi 13 mai 2005

ce coupon-réponse au secrétariat du colloque :

Dynamiques Professionnelles dans le champ de la santé

Market Place

2 bis, avenue Desfeux

92772 Boulogne-Billancourt cedex

Courriel : dynamiques@marketplace.fr

Fax : 0147616861

Le nombre de places étant limité, merci de vous inscrire le plus rapidement possible. 


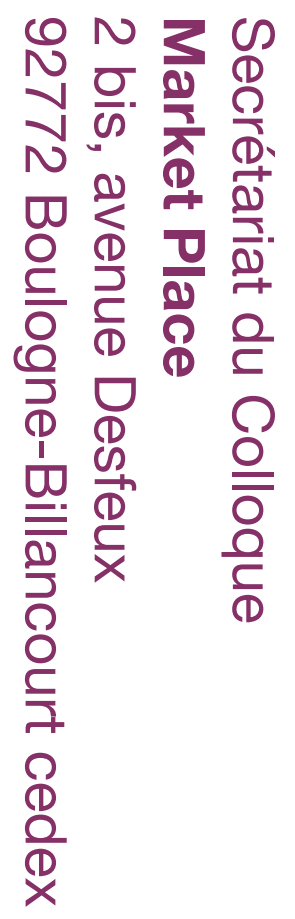

